\title{
Geometric Identification of Carryng Frame of Radial-axial Bearing at Hydraulic Excavators
}

\author{
Milomir Gašić1 $^{*}$, Mile Savković ${ }^{1}$, Goran Marković1 ${ }^{1}$ Nebojša Zdravković1 \\ ${ }^{1}$ University of Kragujevac, Faculty of Mechanical and Civil Engineering in Kraljevo,Serbia
}

Rotating and stationary parts of some building and transport machines (excavators, portal cranes, column cranes) are connected by radial-axial bearings of big diameters which transfer not only forces but moments as well. The paper shows the research results of relations among geometric dimensions of carrying frame elements which are important for reliable functioning of the bearings. The first part of the paper deals with theoretical analysis of the influence of relations between these geometric dimensions on rigidity of the carrying frame of excavators. The second part of the paper presents the experimental analysis of changes in rigidity relation depending on characteristic parameters of realized structures of two carrying frames of excavators. Comparative analysis of theoretical and experimental results has shown a high reliability and confirmed theoretical relations defined in the paper.

Keywords: carrying frame, excavator, rigidity, bearing, experiment

\section{INTRODUCTION}

Rotating platform and carrying structure of some building and transport machines, such as hydraulic excavators, rotor excavators, portal cranes, column cranes, are connected by radial-axial bearings having big diameters (Fig. 1). Manufacturers who produce these bearings [1], define the conditions regarding their lifetime and reliability. These bearings have small dimensions of cross section in comparison to diameter, i.e. their rigidity can not prevent deplanation of the plane in which bearing elements move (balls or rolls). Thus, rigidity of carrying frame has to meet some conditions for reliable transfer of forces and moments when the excavator platform rotates [2] and [3]. The paper analyses theoretical relations among geometrical dimensions of carrying frame elements which have important influence on frame rigidity. These results have been verified by laboratory measurements made on the frames of realized structures.

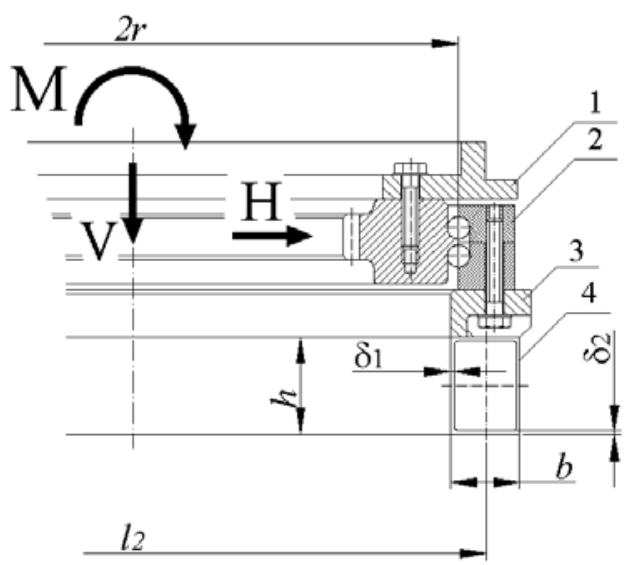

1. rotating platform; 2. radial-axial bearing;

3. radial-axial bearing support; 4 . carrying frame of excavator

Fig. 1. Connection between rotating platform and carrying frame

\section{MODEL DEFINING}

If relations among geometric dimensions of carrying frame of radial-axial bearing are analysed, geometric dimensions of carrying frame which provide efficient distribution of load along the circumference of the bearing can be defined [4], [5], and [6]. Loads, which are transferred from rotating platform to the carrying frame, are shown in Fig. 1. Basic geometric dimensions of cross section elements of carrying frame are also presented in Fig. 1.

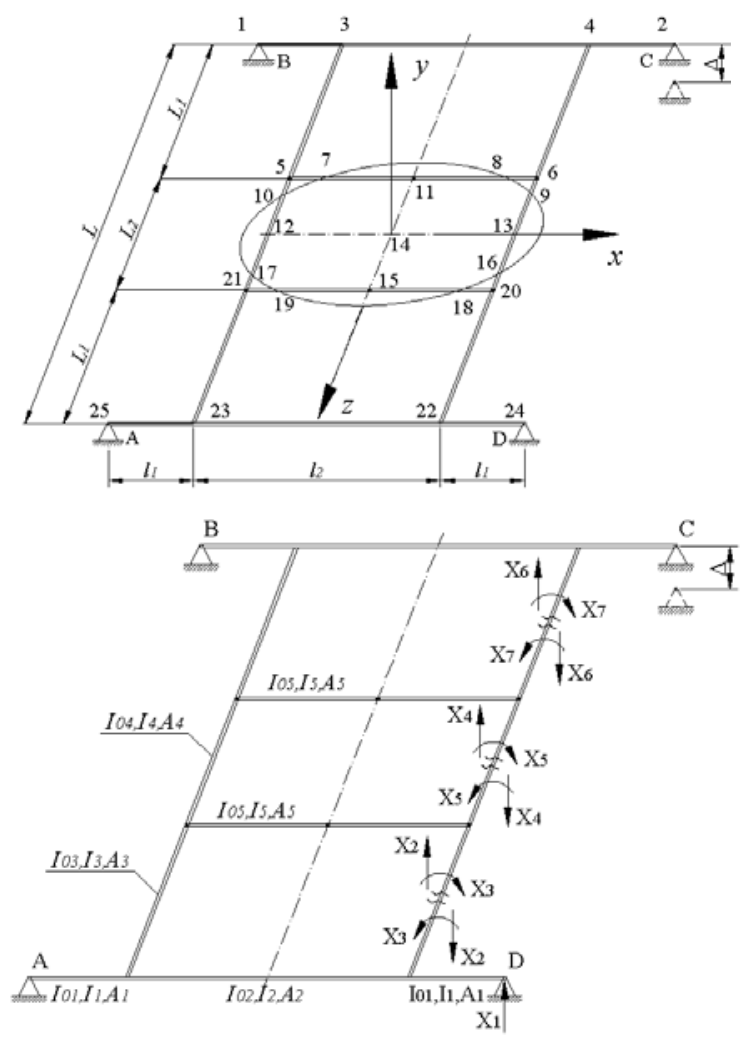

Fig. 2. Model of excavator carrying frame

\footnotetext{
* Corr. Author's Address: University of Kragujevac, Faculty of Mechanical engineering Kraljevo, Dositejeva 19, Serbia, gasic.m@mfkv.kg.ac.rs
} 
When excavator is operating there is an inclination of its carrying structure because of the lowering of a support and predistribution of vertical loads, as a result of basic elements deformations. For example, if support $C$ is lowered for $\Delta$ value (Fig. 2,a), the basic system has the form presented in Fig. 2,b, where an unknown value $X_{1}$ and $X_{i}(i=2, \ldots, 7)$ are introduced instead of support D and rejected connections, respectively.

The system of canonical equations for the system shown in Fig. 2, b is:

$$
A \cdot \vec{X}=\vec{\Delta}
$$

where:

$A$ - square matrix, consisted of influential coefficients, $\vec{X}$ - vector of unknown forces and moments,

$\vec{\Delta}$ - vector of free members.

Influential coefficients $\delta_{i k}(i=1,2, \ldots, 7 ; \quad k=1,2, \ldots, 7)$ which represent the members of square matrix $A$, can be determined by Mohr's integral [7].

$$
\begin{aligned}
\delta_{i k} & =\int_{l} \frac{M_{t k} \cdot M_{t i}}{G \cdot I_{0}} \cdot d x+\int_{l} \frac{M_{z k} \cdot M_{z i}}{G \cdot I_{z}} \cdot d x+\int_{l} \frac{M_{y k} \cdot M_{y i}}{G \cdot I_{y}} \cdot d x+ \\
& +\int_{l} \frac{N_{k} \cdot N_{i}}{E \cdot a} \cdot d x+\int_{l} \frac{K_{z} \cdot Q_{z k} \cdot Q_{z i}}{G \cdot A} \cdot d x+\int_{l} \frac{K_{y} \cdot Q_{y k} \cdot Q_{y i}}{G \cdot A} \cdot d x
\end{aligned}
$$

Since tension and shearing influences are far smaller than bending and torsion influences, the last three integrals are neglected in further analysis. Vereschagin's procedure can be used to solve expression (2). If relation between geometrical parameters of carrying frame elements is introduced the following relations can be defined (Fig. 2).

$$
\begin{array}{llll}
\psi=L_{1} / L_{2} ; & \eta=I_{5} / I_{2} ; & \beta=I_{4} / I_{2} ; & \lambda=\delta_{2} / \delta_{1} ; \\
\varphi=I_{3} / I_{2} ; & w=l_{1} / l_{2} ; & I_{2}=I_{1} ; & k=h / b ;
\end{array}
$$

Influential coeffcients $\delta_{i k}$ are:

$$
\begin{gathered}
\delta_{11}=\frac{4 w^{3} l_{2}^{3}}{3 E I_{2}}+\frac{2 w l_{2}^{3}}{E I_{2}} \cdot\left(1+w+\frac{1}{3 w}\right)+\frac{2 \mu \psi L_{2} l_{2}}{\varphi E I_{2}}+\frac{\mu L_{2} l_{2}}{\beta E I_{2}} ; \\
\delta_{12}=\frac{l_{2}^{3}}{6 E I_{2}}(3 w+2) ; \delta_{13}=-\frac{l_{2}^{2}}{2 E I_{2}}(2 w+1)-\frac{\mu \psi L_{2} l_{2}}{\varphi E I_{2}} ; \\
\delta_{14}=0 ; \quad \delta_{15}=-\frac{\mu L_{2} l_{2}}{\beta E I_{2}} ; \quad \delta_{16}=\delta_{12} ; \quad \delta_{17}=\delta_{13} ; \\
\delta_{22}=\left(1+\frac{1}{\eta}\right)\left[\frac{l_{2}^{3}}{3 E I_{2}}+\frac{\mu \psi^{2} L_{2}^{2} l_{2}}{4 E I_{2}}\right]+\frac{\psi^{3} L_{2}^{3}}{6 \varphi E I_{2}} ; \\
\delta_{23}=-\frac{l_{2}^{2}}{2 E I_{2}}\left(1+\frac{1}{\eta}\right) ; \quad \delta_{24}=\frac{l_{2}^{3}}{3 \eta E I_{2}}+\frac{\mu \psi L_{2}^{3} l_{2}}{4 \eta E I_{2}} ; \\
\delta_{25}=\frac{l_{2}^{3}}{2 \eta E I_{2}} ; \quad \delta_{26}=0 ; \quad \delta_{27}=0 ; \\
\delta_{33}=\frac{l_{2}}{E I_{2}}\left(1+\frac{1}{\eta}\right)+\frac{2 \mu \psi L_{2}}{\varphi E I_{2}} ; \delta_{34}=\frac{l_{2}^{2}}{2 \eta E I_{2}} ;
\end{gathered}
$$

$$
\begin{aligned}
& \delta_{35}=-\frac{l_{2}}{\eta E I_{2}} ; \quad \delta_{36}=0 ; \quad \delta_{37}=0 ; \\
& \delta_{44}=\frac{2 l_{2}^{3}}{3 \eta E I_{2}}+\frac{L_{2}^{3}}{6 \beta E I_{2}}+\frac{\mu L_{2}^{2} l_{2}}{2 \eta E I_{2}} ; \\
& \delta_{45}=-\frac{l_{2}^{2}}{\eta E I_{2}} ; \quad \delta_{46}=\delta_{24} ; \quad \delta_{47}=\delta_{34} ; \\
& \delta_{55}=\frac{2 l_{2}}{\eta E I_{2}}+\frac{2 \mu L_{2}}{\eta E I_{2}} ; \delta_{56}=\delta_{34}=\delta_{25} ; \\
& \delta_{57}=\delta_{35} ; \quad \delta_{66}=\delta_{22} ; \quad \delta_{67}=\delta_{23} ; \quad \delta_{77}=\delta_{33} ;
\end{aligned}
$$

The system of canonical equations (1) is solved by programme DELTA 3 [8]. The following coefficients are varied:

$k=1.0,1.5,2.0,2.5,3.0,3.5$;

$\psi=0.0,0.2,0.4,0.6,0.8,1.0$;

$\beta=1.0,1.5,2.0,2.5$;

$\delta=10,15,20,25,30$;

$\lambda=1.0,1.5,2.0,2.5$;

$\varphi=1.0,1.5,2.0,2.5$

$\eta,=1.0,1.5,2.0,2.5$

$w=0.4,0.6,0.8,1.0$;

\section{RIGIDITY OF CARRYING FRAME DEPENDING ON CHANGES OF CHARACTERISTIC PARAMETERS}

If research results obtained by programme DELTA 3 are analysed, functional relations between rigidity and geometrical dimensions of carrying frame can be defined.The analysis has been made under following conditions:

a) constant geometrical dimensions:

$b$ - width of box-like member of carrying frame,

$\delta_{1}, \delta_{2}$ - thicknesses of vertical and horizontal sheet of box-like members of carrying frame,

$l_{2}$ - distance between cross members of carrying frame,

$L_{2}$ - distance between intermediate longitudinal members of carrying frame,

$\Delta$ - clearance at support $C$ of carrying frame.

b) constant coefficients:

$k$ - relation between height and width of box-like member of carrying frame,

$\lambda$ - relation between thicknesses of horizontal and vertical sheets of box-like member of carrying frame.

c) variable coefficients:

$\eta, \beta, w, \varphi, \psi$ - defined by relations 3 .

\subsection{Influence of changes in coefficient $\lambda$ on rigidity of carrying frame}

Fig. 3-6 shows the influences of characteristic parameters on the rigidity of carrying frame, presented by additional force at support $D$ with defined clearance $\Delta$. When coefficient $\lambda$ is increased the rigidity of carrying frame is also increased. The change in relation between rigidities of carrying frame has the same form if $\lambda$ is bigger than 1.5 , so these changes in relations are not presented in the paper. 
Following conclusions can be made on the basis of results presented in diagrams:

1. If coefficient $\beta$ is increased, the rigidity of carrying frame is also increased, but the maximum coefficient of rigidity increase is $\beta=1 \div 1.5$;

2 . If coefficient $\omega$ is increased, the rigidity of carrying frame is decreased. The coefficient of rigidity decrease is visible for $\omega=0.4 \div 0.6$. If $\omega=0.8 \div 1$ the change in rigidity is four times smaller than previous values.

3. If coefficient $\psi$ is increased, the rigidity of carrying frame is decreased. Decrease coefficient is almost negligible for $\psi=0.8 \div 1.0$.

4. If coefficient $\varphi$ is increased, the rigidity of carrying frame is increased whereas increase coefficient is almost constant for the same value of coefficient $\varphi$.

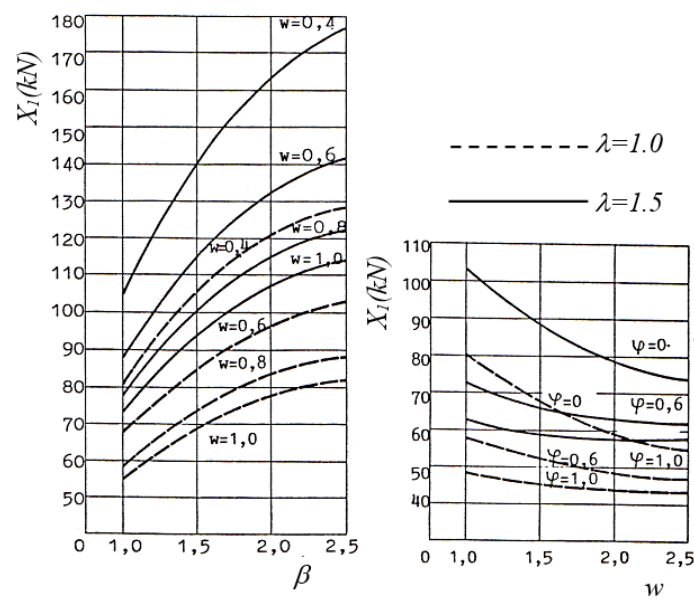

Fig. 3. The values of $X_{1}$ depending of coefficient $\beta, w$ i $\varphi$
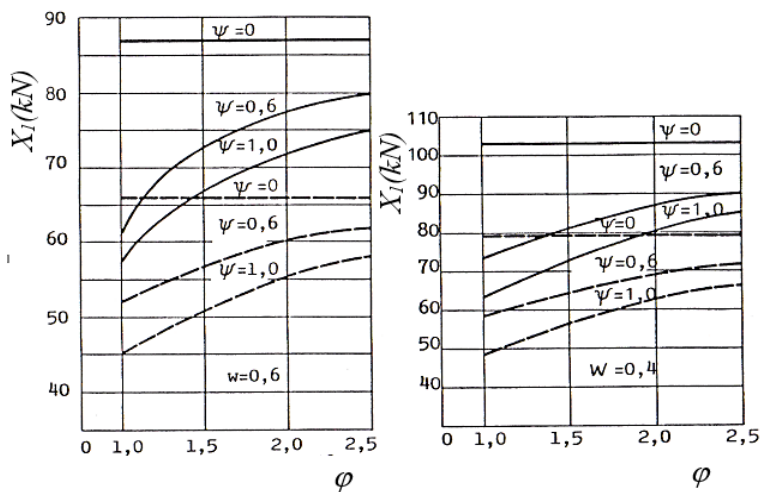

Fig. 4. The values of $X_{1}$ depending of coefficient $\varphi$ i $\psi$
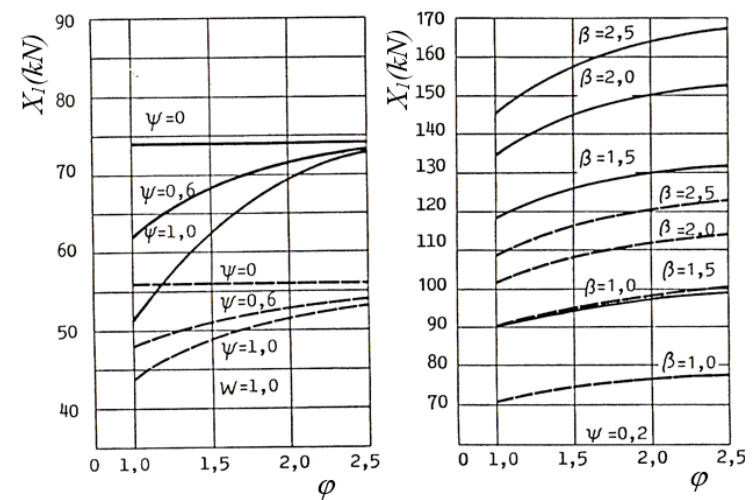

Fig. 5. The values of $X_{1}$ depending of coefficient $\varphi, \beta$ i $\psi$
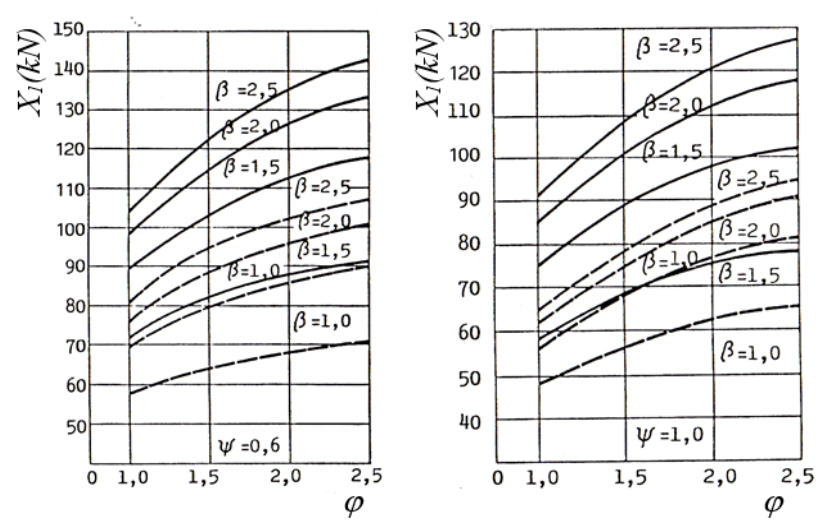

Fig. 6. The values of $X_{1}$ in function of coefficient $\varphi, \beta$ i $\psi$

\subsection{Influence of changes in coefficient $k$ on rigidity of carrying frame}

If results obtained by programme DELTA 3 are used, it is possible to define the relations between frame rigidities depending on changes in coefficient $k$. The research has been done for the following values of coefficient $k=1.0 ; 2.0 ; 3.0$, for different geometric characteristics of members $L_{2}$ and $l_{2}$, and for different coefficients $\psi$ and $w$. Tables 1,2,3,4,5 and 6 show the values of forces at support $D$ with constant clearance at support $C$ for $w=0,5$ and $w=1,0$.

Table 1. The values of $X_{k 1}$ forces

\begin{tabular}{|c|c|c|c|c|c|c|}
\hline \multirow{3}{*}{} & \multicolumn{7}{|c|}{$w=0.5$} \\
\cline { 2 - 7 } & $L_{2}$ & $l_{2}$ & $\psi$ & $X_{k 1}$ & $C_{k 2} / C_{k 1}$ & $\left(k_{2} / k_{1}\right)^{\sqrt{3}}$ \\
\hline \hline \multirow{5}{*}{$k_{1}=1$} & 1000 & 1000 & 0.5 & 57.16 & 3.34 & \\
\cline { 2 - 6 } & 1000 & 1000 & 1.0 & 46.75 & 3.10 & \\
\cline { 2 - 6 } & 2000 & 2000 & 0.5 & 7.09 & 3.34 & \multirow{4}{*}{3.32} \\
\cline { 2 - 6 } & 2000 & 2000 & 1.0 & 5.79 & 3.10 & \\
\cline { 2 - 6 } & 5000 & 5000 & 0.5 & 0.45 & 3.35 & \\
\cline { 2 - 6 } & 5000 & 5000 & 1.0 & 0.37 & 3.10 & \\
\hline
\end{tabular}

Table 2. The values of $X_{k 2}$ forces

\begin{tabular}{|l|l|l|c|c|c|c|}
\hline & \multicolumn{6}{|c|}{$w=0.5$} \\
\cline { 2 - 6 } & $L_{2}$ & $l_{2}$ & $\psi$ & $X_{k 2}$ & $C_{k 3} / C_{k 2}$ & $\left(k_{3} / k_{2}\right)^{\sqrt{3}}$ \\
\hline \hline \multirow{5}{*}{$k_{2}=2$} & 1000 & 1000 & 0.5 & 191.37 & 2.02 & \\
\cline { 2 - 6 } & 1000 & 1000 & 1.0 & 144.67 & 1.95 & \\
\cline { 2 - 6 } & 2000 & 2000 & 0.5 & 23.70 & 2.02 & \multirow{4}{*}{2.02} \\
\cline { 2 - 6 } & 2000 & 2000 & 1.0 & 17.91 & 1.95 & \\
\cline { 2 - 6 } & 5000 & 5000 & 0.5 & 1.51 & 2.02 & \\
\cline { 2 - 6 } & 5000 & 5000 & 1.0 & 1.14 & 1.95 & \\
\hline
\end{tabular}

Table 3. The values of $X_{k 3}$ forces

\begin{tabular}{|l|l|l|l|l|l|l|}
\hline & \multicolumn{7}{|c|}{$w=0.5$} \\
\cline { 2 - 6 } & $L_{2}$ & $l_{2}$ & $\psi$ & $X_{k 3}$ & $C_{k 3} / C_{k 1}$ & $\left(k_{3} / k_{1}\right)^{\sqrt{3}}$ \\
\hline \hline \multirow{5}{*}{$k_{3}=3$} & 1000 & 1000 & 0.5 & 386.45 & 6.76 & \\
\cline { 2 - 6 } & 1000 & 1000 & 1.0 & 281.90 & 6.03 & \multirow{4}{*}{6.7} \\
\cline { 2 - 6 } & 2000 & 2000 & 0.5 & 47.85 & 6.75 & \\
\cline { 2 - 6 } & 2000 & 2000 & 1.0 & 34.89 & 6.03 & \\
\cline { 2 - 6 } & 5000 & 5000 & 0.5 & 3.05 & 6.77 & \\
\cline { 2 - 5 } & 5000 & 5000 & 1.0 & 2.22 & 6.00 & \\
\hline
\end{tabular}


The values shown in tables 1,2 and 3 are related to: $w=0,5$

$b=300 \mathrm{~mm}$ - width of box-like member of carrying frame;

$\delta_{1}=10 \mathrm{~mm}$ - thickness of vertical sheet of box-like member of carrying frame;

$\Delta=5 \mathrm{~mm}$ - clearance at support $C$.

The values shown in tables 4,5 , and 6 are related to:

$w=1,0$

$b=300 \mathrm{~mm}$ - width of box-like member of carrying frame;

$\delta_{1}=10 \mathrm{~mm}$ - thickness of vertical sheet of box-like member of carrying frame;

$\Delta=5 \mathrm{~mm}$ - clearance at support C.

Table 4. The values of $X_{k 1}$ forces

\begin{tabular}{|c|l|l|l|l|l|l|}
\hline \multirow{5}{*}{} & \multicolumn{7}{|c|}{$w=1$} \\
\cline { 2 - 6 } & $L_{2}$ & $l_{2}$ & $\psi$ & $X_{k 1}$ & $C_{k 2} / C_{k 1}$ & $\left(k_{2} / k_{1}\right)^{\sqrt{3}}$ \\
\hline \hline \multirow{5}{*}{$k_{1}=1$} & 1000 & 1000 & 0.5 & 49.72 & 3.60 & \\
\cline { 2 - 6 } & 1000 & 1000 & 1.0 & 43.94 & 3.23 & \multirow{4}{*}{3.32} \\
\cline { 2 - 6 } & 2000 & 2000 & 0.5 & 6.15 & 3.60 & \\
\cline { 2 - 6 } & 2000 & 2000 & 1.0 & 5.43 & 3.23 & \\
\cline { 2 - 6 } & 5000 & 5000 & 0.5 & 0.39 & 3.61 & \\
\cline { 2 - 6 } & 5000 & 5000 & 1.0 & 0.35 & 3.20 & \\
\hline
\end{tabular}

Table 5. The values of $X_{k 2}$ forces

\begin{tabular}{|l|l|l|l|l|l|l|}
\hline \multirow{5}{*}{} & \multicolumn{6}{|c|}{$w=1$} \\
\cline { 2 - 6 } & $L_{2}$ & $l_{2}$ & $\psi$ & $X_{k 2}$ & $C_{k 3} / C_{k 2}$ & $\left(k_{3} / k_{2}\right)^{\sqrt{3}}$ \\
\hline \hline \multirow{5}{*}{$k_{2}=2$} & 1000 & 1000 & 0.5 & 179.23 & 2.07 & \\
\cline { 2 - 6 } & 1000 & 1000 & 1.0 & 142.19 & 1.97 & \\
\cline { 2 - 6 } & 2000 & 2000 & 0.5 & 22.16 & 2.07 & \multirow{4}{*}{} \\
\cline { 2 - 6 } & 2000 & 2000 & 1.0 & 17.57 & 1.97 & \\
\cline { 2 - 6 } & 5000 & 5000 & 0.5 & 1.41 & 2.07 & \\
\cline { 2 - 6 } & 5000 & 5000 & 1.0 & 1.12 & 1.96 & \\
\hline
\end{tabular}

Table 6. The values of $X_{k 3}$ forces

\begin{tabular}{|c|l|l|l|l|l|l|}
\hline \multirow{5}{*}{} & \multicolumn{7}{|c|}{$w=1$} \\
\cline { 2 - 6 } & $L_{2}$ & $l_{2}$ & $\psi$ & $X_{k 3}$ & $C_{k 3} / C_{k 1}$ & $\left(k_{3} / k_{1}\right)^{\sqrt{3}}$ \\
\hline \hline \multirow{5}{*}{$k_{3}=3$} & 1000 & 1000 & 0.5 & 372.06 & 7.48 & \\
\cline { 2 - 6 } & 1000 & 1000 & 1.0 & 280.85 & 6.38 & \\
\cline { 2 - 6 } & 2000 & 2000 & 0.5 & 46.00 & 7.48 & \multirow{4}{*}{6.7} \\
\cline { 2 - 6 } & 2000 & 2000 & 1.0 & 34.66 & 6.38 & \\
\cline { 2 - 6 } & 5000 & 5000 & 0.5 & 2.93 & 7.51 & \\
\cline { 2 - 6 } & 5000 & 5000 & 1.0 & 2.20 & 6.28 & \\
\hline
\end{tabular}

If relation between coefficients $k$ is increased, then relation between rigidities of carrying frame is also increased according to the following relation:

$$
\frac{C_{k i}}{C_{k j}}=\left(\frac{k_{i}}{k_{j}}\right)^{\sqrt{3}}
$$

Fig. 4 shows relations $C_{k 2} / C_{k 1}, C_{k 3} / C_{k 1}$, and $C_{k 3} / C_{k 2}$, for coefficients $\psi=0,5$ and $\psi=1,0 ; w=0,5$ and $w=1,0 ; \quad b=$ const $\quad \Delta=$ const $; \delta_{1}=$ const $; L_{2} / l_{2}=1000,2000 \mathrm{i}$ $5000 \mathrm{~mm}$. Relation $\left(k_{i} / k_{j}\right)^{\sqrt{3}}$ is presented, too.


Fig. 7. Diagrams of changes in rigidity of carrying frame depending on coefficient $k$

\subsection{Influence of changes in geometrical values $L$ and $I$ on rigidity of carrying frame}

Relation of changes in rigidity of carrying frame can be defined depending on changes in geometrical values of $L$ and $l$ for different parameters of $\psi$ abd $w$. Tables 7 and 8 show the force values at support $D$, for constant clearance at support $C$ for values $w=0,5$ and $w=1,0 ; \delta=10 \mathrm{~mm} ; k=1,0 ; \lambda=1,0 ; \quad b=300 \mathrm{~mm}$; and for $w=0,4$ i $w=0,7 ; \delta=10 \mathrm{~mm} ; k=3,0 ; \lambda=1,5 ; b=300 \mathrm{~mm}$.

Table 7. The force values at support $D ; \Delta=$ const, $w=0.5 ; 1$ i $\psi=0 ; 0,5 ; 1$

\begin{tabular}{|c||c|c|c|c|c|c|}
\hline & \multicolumn{3}{|c|}{$w=0.5$} & \multicolumn{3}{c|}{$w=1.0$} \\
\hline$I_{2, L} L_{2}$ & $\psi=0$ & $\psi=0.5$ & $\psi=1$ & $\psi=0$ & $\psi=0.5$ & $\psi=1$ \\
\hline \hline $\begin{array}{c}1000, \\
1000\end{array}$ & 72.46 & 57.16 & 46.75 & 54.85 & 49.72 & 43.94 \\
\hline $\begin{array}{c}2000, \\
2000\end{array}$ & 8.99 & 7.09 & 5.79 & 6.79 & 6.15 & 5.43 \\
\hline $\begin{array}{c}3000, \\
3000\end{array}$ & 2.66 & 2.09 & 1.72 & 2.01 & 1.83 & 1.61 \\
\hline $\begin{array}{c}4000, \\
4000\end{array}$ & 1.1 & 0.88 & 0.72 & 0.85 & 0.77 & 0.68 \\
\hline $\begin{array}{c}5000, \\
5000\end{array}$ & 0.57 & 0.45 & 0.37 & 0.43 & 0.39 & 0.35 \\
\hline
\end{tabular}


Table 8. The force values at support $D ; \Delta=$ const, $w=0.4 ; 0.7$ i $\psi=0 ; 0,5 ; 1$

\begin{tabular}{|c|c|c|c||c|c|c|}
\hline & \multicolumn{3}{|c|}{$w=0.4=0.7$} \\
\hline$l_{2}, L_{2}$ & $\psi=0$ & $\psi=0.5$ & $\psi=1$ & $\psi=0$ & $\psi=0.5$ & $\psi=1$ \\
\hline \hline $\begin{array}{c}1000, \\
1000\end{array}$ & 713.98 & 435.85 & 311.32 & 629.83 & 412.85 & 302.03 \\
\hline $\begin{array}{c}2000, \\
2000\end{array}$ & 88.47 & 53.96 & 38.54 & 78.02 & 51.10 & 37.38 \\
\hline $\begin{array}{c}3000, \\
3000\end{array}$ & 26.14 & 15.94 & 11.38 & 23.05 & 15.09 & 11.04 \\
\hline $\begin{array}{c}4000, \\
4000\end{array}$ & 11.01 & 6.71 & 4.79 & 9.71 & 6.35 & 4.65 \\
\hline $\begin{array}{c}5000, \\
5000\end{array}$ & 5.63 & 3.43 & 2.45 & 4.96 & 3.25 & 2.38 \\
\hline
\end{tabular}

Tables 9 and 10 show that the increase of distance $L$ for constant values of $w, \delta, k, \lambda$ and $b$ causes the decrease of relation between rigidities of carrying frames according to following relation:

$$
\left(C_{L i} / C_{L j}\right)=\left(L_{j} / L_{i}\right)^{3}
$$

Relations $\left(C_{L i} / C_{L j}\right)$ depending on coefficients $\varphi, \psi$, $w, k$ and $\lambda$, for constant values of $b, \delta_{1}$ and $\Delta$ are presented in tables 9 and 10 . Values of $\left(L_{j} / L_{i}\right)^{3}$ are shown, too.

Table 9. The relations $\left(C_{L i} / C_{L j}\right)$ depending on coefficient $\varphi, \psi, w, k=1$ i $\lambda=1 ; b=$ const, $\delta_{1}=$ const and $\Delta=$ const

\begin{tabular}{|l|c|c|c|c|c|c|c|}
\hline \multicolumn{7}{|c|}{$k=1.0 ; \lambda=1.0 ;$} \\
\hline \multirow{2}{*}{$\mathrm{C}_{\mathrm{L} i} / \mathrm{C}_{\mathrm{Lj}}$} & \multicolumn{3}{|c|}{$w=0.5$} & \multicolumn{3}{c|}{$w=1.0$} & $\left(L_{j} / L_{i}\right)^{3}$ \\
\cline { 2 - 8 } & $\psi=0$ & $\psi=0.5$ & $\psi=1$ & $\psi=0$ & $\psi=0.5$ & $\psi=1$ & \\
\hline \hline $\mathrm{C}_{\mathrm{L} 1} / \mathrm{C}_{\mathrm{L} 2}$ & 8.06 & 8.06 & 8.07 & 8.07 & 8.08 & 8.09 & 8 \\
\hline $\mathrm{C}_{\mathrm{L} 1} / \mathrm{C}_{\mathrm{L} 3}$ & 27.24 & 27.34 & 27.18 & 27.28 & 27.16 & 27.29 & 27 \\
\hline $\mathrm{C}_{\mathrm{L} 1} / \mathrm{C}_{\mathrm{L} 4}$ & 65.28 & 64.95 & 64.93 & 64.53 & 64.57 & 64.61 & 64 \\
\hline $\mathrm{C}_{\mathrm{L} 1} / \mathrm{C}_{\mathrm{L} 5}$ & 127.12 & 127.02 & 126.35 & 127.55 & 127.48 & 125.54 & 125 \\
\hline $\mathrm{C}_{\mathrm{L} 2} / \mathrm{C}_{\mathrm{L} 3}$ & 3.37 & 3.39 & 3.36 & 3.37 & 3.36 & 3.37 & 3.375 \\
\hline $\mathrm{C}_{\mathrm{L} 2} / \mathrm{C}_{\mathrm{L}}$ & 8.09 & 8.05 & 8.04 & 7.99 & 7.99 & 7.98 & 8 \\
\hline $\mathrm{C}_{\mathrm{L} 2} / \mathrm{C}_{\mathrm{L} 5}$ & 15.77 & 15.75 & 15.65 & 15.79 & 15.77 & 15.51 & 15.625 \\
\hline $\mathrm{C}_{\mathrm{L} 3} / \mathrm{C}_{\mathrm{L} 4}$ & 2.39 & 2.37 & 2.38 & 2.36 & 2.37 & 2.36 & 2.37 \\
\hline $\mathrm{C}_{\mathrm{L} 3} / \mathrm{C}_{\mathrm{L} 5}$ & 4.66 & 4.64 & 4.65 & 4.67 & 4.69 & 4.60 & 4.629 \\
\hline $\mathrm{C}_{\mathrm{L} 4} / \mathrm{C}_{\mathrm{L} 5}$ & 1.95 & 1.95 & 1.94 & 1.97 & 1.97 & 1.94 & 1.953 \\
\hline
\end{tabular}

Table 10. The relations $\left(C_{L i} / C_{L j}\right)$ depending on coefficient $\varphi, \psi, w, k=3 i \lambda=1.5 ; b=$ const, $\delta_{1}=$ const and $\Delta=$ const

\begin{tabular}{|l|c|c|c|c|c|c|c|}
\hline \multicolumn{7}{|c|}{$k=3.0 ; \quad \lambda=1.5 ;$} \\
\hline \multirow{2}{*}{$\mathrm{C}_{\mathrm{Li}} / \mathrm{C}_{\mathrm{Lj}}$} & \multicolumn{3}{|c|}{$W=0.4$} & \multicolumn{3}{c|}{$W=0.7$} & $\left(L_{j} / L_{i}\right)^{3}$ \\
\cline { 2 - 8 } & $\psi=0$ & $\psi=0.5$ & $\psi=1$ & $\psi=0$ & $\psi=0.5$ & $\psi=1$ & \\
\hline $\mathrm{C}_{\mathrm{L} 1 / \mathrm{C}_{\mathrm{L} 2}}$ & 8.07 & 8.07 & 8.08 & 8.07 & 8.08 & 8.09 & 8 \\
\hline $\mathrm{C}_{\mathrm{L} 1} / \mathrm{C}_{\mathrm{L} 3}$ & 27.31 & 27.34 & 27.35 & 27.32 & 27.36 & 27.35 & 27 \\
\hline $\mathrm{C}_{\mathrm{L} 1} / \mathrm{C}_{\mathrm{L} 4}$ & 64.85 & 64.95 & 64.99 & 64.86 & 65.01 & 64.95 & 64 \\
\hline $\mathrm{C}_{\mathrm{L} 1} / \mathrm{C}_{\mathrm{L} 5}$ & 126.81 & 127.07 & 127.07 & 126.98 & 127.03 & 126.90 & 125 \\
\hline $\mathrm{C}_{\mathrm{L} 2} / \mathrm{C}_{\mathrm{L} 3}$ & 3.38 & 3.38 & 3.38 & 3.38 & 3.38 & 3.38 & 3.375 \\
\hline $\mathrm{C}_{\mathrm{L} 2} / \mathrm{C}_{\mathrm{L} 4}$ & 8.03 & 8.04 & 8.04 & 8.03 & 8.05 & 8.04 & 8 \\
\hline $\mathrm{C}_{\mathrm{L} 2} / \mathrm{C}_{\mathrm{L} 5}$ & 15.71 & 15.73 & 15.73 & 15.73 & 15.72 & 15.70 & 15.625 \\
\hline $\mathrm{C}_{\mathrm{L} 3} / \mathrm{C}_{\mathrm{L} 4}$ & 2.37 & 2.37 & 2.37 & 2.37 & 2.38 & 2.37 & 2.37 \\
\hline $\mathrm{C}_{\mathrm{L} 3} / \mathrm{C}_{\mathrm{L} 5}$ & 4.64 & 4.64 & 4.65 & 4.65 & 4.64 & 4.64 & 4.629 \\
\hline $\mathrm{C}_{\mathrm{L} 4} / \mathrm{C}_{\mathrm{L} 5}$ & 1.95 & 1.96 & 1.95 & 1.96 & 1.95 & 1.95 & 1.953 \\
\hline
\end{tabular}

\section{EXPERIMENT AND RESULTS}

Experimental verification has been made in order to verify theoretical results which are related to the rigidity of carrying frame. The experiment has been made on two carrying frames of excavators, types BGH 600 and BGH 10000, made by IMK 14. oktobar, Serbia [9]. The carrying frames are supported by steel spheres, sets of sheet metal of various thicknesses, force transducers, basic plates lying on reinforced concrete basis. One of supports is shown in Fig. 8. Sheet metal sets consist of various thicknesses of plates so that clearance $\Delta$ between frame supports and steel spheres can be achieved by drawing some plates.

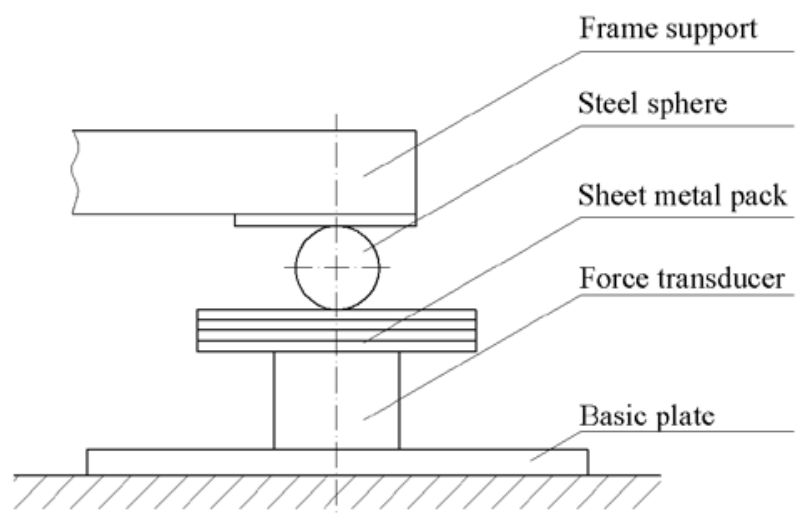

Fig. 8. One of frame supports

Instrumentation and measuring points are shown in Figs.7, 8 and 9, respectively.

The experiment has been made when carrying frame is supported by supports and when one of them is lowered for value $\Delta$ in comparison to other supports. The frame is loaded by the weight of rotating platform along with operating equipment and additional load [11]. Rotation has been made in each $45^{\circ}$.

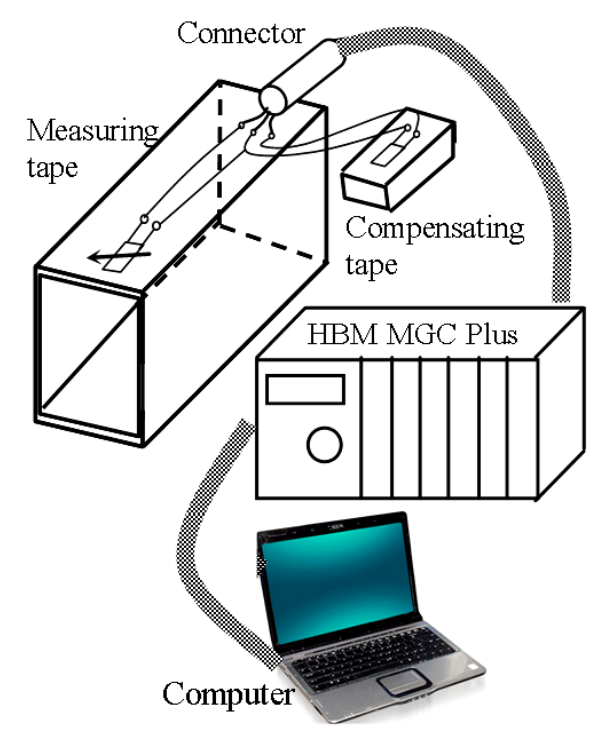

Fig. 9. Layout of connection between measuring devices[10] 


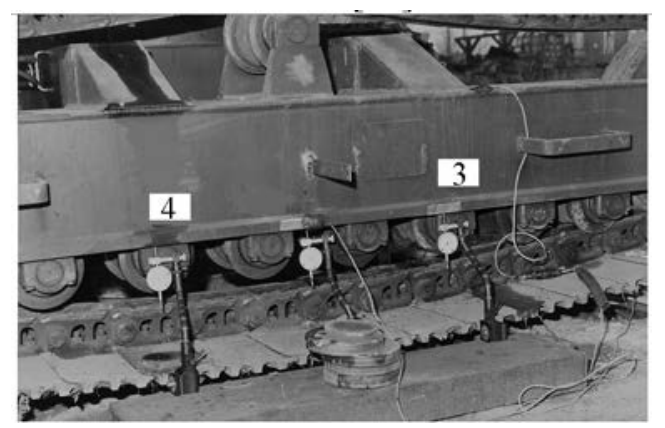

Fig. 10. Measurement of displacements of characteristic points of carrying frame



Fig. 11. Point 2 of measurement of displacements

A series of results have been obtained in the experiment in conformity with defined programme. The paper shows the results which are significant for experimental verification of theoretical model. Thus, comparative results are obtained for displacements of characteristic points (Fig. 2b) of carrying frames, types BGH 600 and BGH 100, made by IMK 14.oktobar, Serbia. For distances $L=2250 \mathrm{~mm}$ (BGH 600) and $L=2410 \mathrm{~mm}$ (BGH 1000) displacements of characteristic points are shown in table 11.

Displacements $f_{I}$ and $f_{I I}$ at support 2 are important for further analysis of experimental results.

If relation (5) is applied:

$$
\begin{gathered}
\left(\frac{L_{I I}}{L_{I}}\right)^{3}=\frac{C_{I}}{C_{I I}}=\frac{f_{I I}}{f_{I}} \\
\left(\frac{2410}{2250}\right)^{3}=\frac{-2.91}{-2.40} \\
1.23 \cong 1.21
\end{gathered}
$$

Theoretical relation (4) and measurement results show high compatibility. The following relations are based on geometrical characteristics of carrying frame:

$$
\begin{aligned}
& \left(\frac{k_{I}}{k_{I I}}\right)^{\sqrt{3}}=\frac{C_{k I}}{C_{k I I}}=\frac{f_{I I}}{f_{I}} \\
& \left(\frac{0.857}{0.767}\right)^{\sqrt{3}}=\frac{-2.91}{-2.40}
\end{aligned}
$$

\begin{tabular}{|c|c|c|}
\hline \multirow{2}{*}{$\begin{array}{c}\text { Characteristic } \\
\text { points }\end{array}$} & $\begin{array}{c}\text { BGH 600; } \\
\mathrm{L}_{\mathrm{I}}=2250 \text { mm; }\end{array}$ & 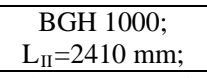 \\
\hline & $\begin{array}{c}\text { Displacements } \\
\mathrm{f}_{\mathrm{I}}(\mathrm{mm})\end{array}$ & $\begin{array}{c}\text { Displacements } f_{\text {II }} \\
(\mathrm{mm})\end{array}$ \\
\hline 2 & -2.40 & -2.91 \\
\hline 3 & -0.94 & -1.12 \\
\hline 4 & -1.69 & -1.90 \\
\hline 5 & -0.69 & -0.78 \\
\hline 6 & -1.29 & -1.38 \\
\hline 7 & -0.51 & -0.60 \\
\hline 8 & -0.97 & -1.07 \\
\hline 9 & -0.61 & -0.74 \\
\hline 10 & -0.33 & -0.42 \\
\hline 11 & -0.1 & -0.15 \\
\hline 12 & -0.05 & -0.10 \\
\hline
\end{tabular}

$1.21=1.21$
Table 11. Displacements of characteristic points of carryng frame

Therefore, theoretical relation (4) is proved, too. The obtained relations can be of great importance for continuation of research taking into account the stiffening ring whose calculation can be performed by using the methodology [12-14] and optimization of mentioned parameters [15].

\section{CONCLUSION}

Theoretical and experimental results clearly define the influence of relation between geometrical dimensions of characteristic parameters of carrying frame on its rigidity. Out of large number of obtained results only the results which are significant for defining the frame rigidity are stated:

- if relation between height and width of members of boxlike cross sections, the relation between rigidities of these members are also increased. The increase of rigidity relation is defined by relation between coefficients $k$ raised to a power $\sqrt{3}$,

- if distance between longitudinal axes of carrying frame is increased, the relation between rigidities is decreased. Decrease relation between frame rigidities is inversely proportional to cubic relation of distance between longitudinal axes of carrying frame.

These results provide forming the excavator carrying frames enabling necessary rigidity of basic surface on which radial-axial bearing is supported. The results are also important for stress analysis of the carrying frames and for defining the stress dissipation in the frame elements.

\section{ACKNOWLEDGEMENT}

This paper is result of technological project No. TR35038, supported by Ministry of Education, Science and Technological Development of the Republic of Serbia. 


\section{REFERENCES}

[1] http://www.rotheerde.com/download/info/Rothe_Erde _GWL_D.pdf

[2] Smolnicki, T., Derlukiewicz, D., Stanco, M.(2008). Evaluation of load distribution in the superstructure rotation joint of single-bucket caterpillar excavators, Automation in construction., vol. no. 17 , p.218-223.

[3] Kania, L. (2006). Modeling of rollers in calculation of slewing bearing with the use of finite elements, Mechanism and Machine Theory. vol. no. 41, p. 1359-1376.

[4] Gašić, M., Savković M., Marković G., Zdravković N.(2009). Analysis of methods for calculating the rings of portal cranes and caterpillars, IMK -14- Researce and development, vol.no. (30-31) p. 37-41. ISSN 03546829 (in Serbian).

[5] Makkonen, T., Nevala, K., Heikkila, R. (2006). A 3D model based control of an excavator. Automation in Construction, vol. no. 57, p. 571-577.

[6] Gašić M., Marković G., Savković M.(2004). A 3D model based control of an excavator, International Conference INTERSTROYMEH Voronež, p. 7-9 UDK 625.76.08 BBK 39.311-06-05+38.6-5, 2004 (in Rusian)

[7] Borjašinov, S.V.(1973) Basics of structural mechanics of machines. Moscow: Machine structure, p. 454 (in Russian) UDK 621.01(075).

[8]Gašić, M., Ivanović, S., SavkovićM.(2008). Programme DELTA 3. Kraljevo: Faculty of Mechanical engineering, (in Serbian) from http://www.mfkv.kg.ac.rs/index.php?option=com_cont ent\&task=view\&id=82\&Itemid=92

[9]Catalogues of Serbian hydraulics excavators manufacturers- "IMK 14 october"
[10] http://www.hbm.com.pl/pdf/b0534.pdf

[11] Towarek, Z. (2003). Dynamics of a single-bucket excavator on a deformable soil foundaion during the digging of ground, Mechanical Sciences. vol. no. 45, p.1053-1076.

[12] Wong, W. C., Azid, I. A., Majlis, B. (2011). Theoretical Analysis of Stiffness Constant and Effective Mass for a Round-Folded Beam in MEMS Accelerometer. Strojniški vestnik - Journal of Mechanical Engineering, vol. no. 57, p. 517-525.

[13] Smolnicki, T. Rusinski, E. (2007). SuperelementBased Modeling of Load Distribution in Large-Size Slewing Bearings. Journal of Mmechanical Design, vol no. 129, p. 459-463.

[14] Gašić, M., Savković, M., Marković G.,Zdravković N. (2010). Research and development of carryng structure of radial-axial bearing of construction and transport mechanization machines. The 6th International Symposium about forming and design in mechanical engineering -KOD 2010, p. 41-48, ISBN 978-86-7892-278-7.

[15] Qian, Z., Xue, C., Pan, S. (2001). FEA agent for multidisciplinary optimization. Structural and Multidisciplinary Optimization, vol no. 22, p. 373383.

[16]Gašić, M., Marković G., Savković M.: Prilog razvoju novog rešenja veze okretnog i neokretnog dela mašina građevinske i transportne mehanizacije, IMK -14Researce and development. 2005, vol (20-21) 12/2005 p.71-76. ISSN 0354-6829 (in Serbian).

[17]Gašić, M., Savković M., Marković G., Zdravković N.: Analiza metoda proračuna prstenova portalnog krana i bagera guseničara, IMK - 14 Research and development. 2009, 


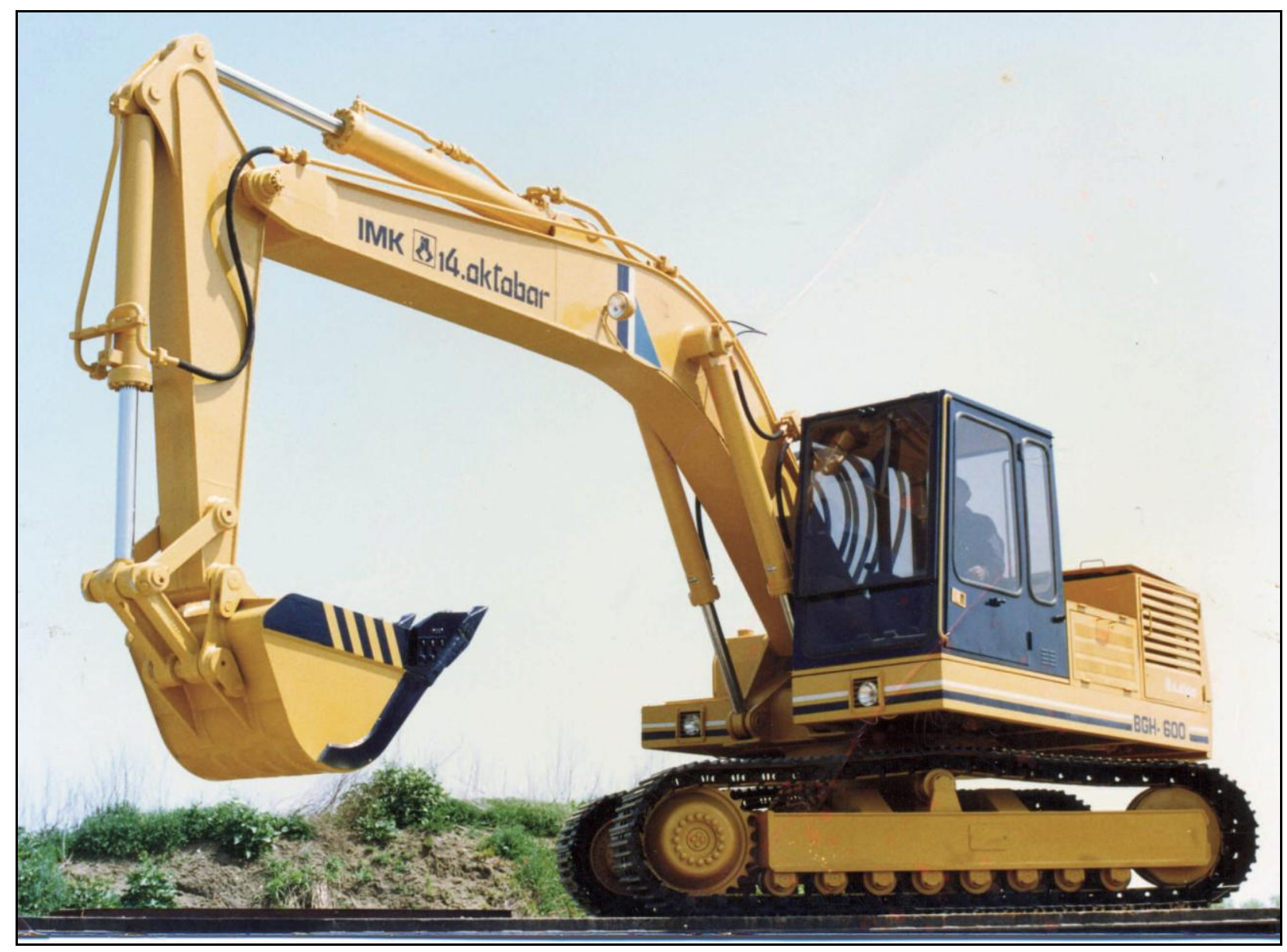

